\title{
A Five-Year Review on Pediatric Foreign Body Aspiration
}

\author{
Zuraini Mohammad Nasir ${ }^{10}$ Sethu Thakachy Subha ${ }^{10}$ \\ ${ }^{1}$ Department of Surgery, Otorhinolaryngology - Head and Neck \\ Surgery Unit, Faculty of Medicine and Health Sciences, University \\ Putra Malaysia, Serdang, Selangor, Malaysia \\ Int Arch Otorhinolaryngol 2021;25(2):e193-e199. \\ Address for correspondence Zuraini Mohammad Nasir, MBBS, MRCS- \\ ENT, Department of Surgery, Otorhinolaryngology - Head and Neck \\ Surgery Unit, Faculty of Medicine and Health Sciences, University \\ Putra Malaysia, Serdang, Selangor, 43400, Malaysia \\ (e-mail: naninasir@gmail.com).
}

\begin{abstract}
Introduction Foreign body aspiration is a leading cause of accidental death in children. Clinical presentation varies from non-specific respiratory symptoms to respiratory failure making diagnosis challenging.

Objective To review pediatric patients who underwent bronchoscopy due to suspicion of foreign body aspiration at a tertiary center in Malaysia.

Methods We retrospectively studied patients $<11$ years old who underwent bronchoscopy from 2008 to 2018.

Results Over the 10-year period, 20 patients underwent bronchoscopy, and 16 were found to have foreign body aspiration with equal gender distribution. The most common age group was $<3$ years old (75\%). The most common clinical presentations were choking (82\%) and stridor (31\%). Foreign bodies were removed using flexible bronchoscope in 8 cases (50\%), and difficulties were encountered in 6 cases (75\%). Rigid ventilating bronchoscope was used in 8 cases (50\%) with no difficulty. The most common object found was peanut (19\%). The majority of foreign bodies were lodged in the right bronchus (43\%). Eight patients (80\%) received delayed treatment due to delayed diagnosis. The length of hospital stay was longer in the younger age groups. Conclusion Clinical presentation and chest radiograph findings were comparable across all age groups. The most difficulties encountered during foreign body removal

Keywords

- foreign bodies

- pediatrics

- bronchoscopy were via flexible bronchoscope, in children $<3$ years old. There was no significant correlation between age and type of foreign body aspiration. The majority of patients who received delayed treatment were $<3$ years old. The length of hospital stay was longer in the younger age groups.
\end{abstract}

\section{Introduction}

Foreign body aspiration in children is a medical emergency that results in high morbidity, ranging from 10 to $20 \%$ worldwide. ${ }^{1}$ In United States alone, foreign body aspiration resulted in thousands of emergency room visits each year accounting for $5 \%$ of all accidental deaths in children under the age of 4 , thus making this problem the leading cause of

received

May 31, 2019

accepted

February 25, 2020

published online

June 23, 2020
DOI https://doi.org/ 10.1055/s-0040-1709739. ISSN 1809-9777. accidental deaths for children under the age of 6. Despite increasing awareness of this problem, the incidence seemed to be on the rise. ${ }^{2}$

Children are known to be susceptible to foreign body aspiration. This is mainly due to the absence of molar teeth, underdeveloped swallowing coordination and the tendency to talk and play while eating. ${ }^{3,4}$ The challenge that is faced by physicians is timely diagnosis for patients who present with (c) 2020. Fundação Otorrinolaringologia. All rights reserved.

This is an open access article published by Thieme under the terms of the Creative Commons Attribution-NonDerivative-NonCommercial-License, permitting copying and reproduction so long as the original work is given appropriate credit. Contents may not be used for commercial purposes, or adapted, remixed, transformed or built upon. (https://creativecommons.org/ licenses/by-nc-nd/4.0/)

Thieme Revinter Publicações Ltda., Rua do Matoso 170, Rio de Janeiro, RJ, CEP 20270-135, Brazil 
partial airway obstruction to ensure the foreign body is safely removed before any complication ensues. This is because the mode of presentation in this group of patients is highly variable. ${ }^{5}$ Presenting symptoms and signs include coughing, dyspnea, wheezing, cyanosis, and stridor, which can mimic a myriad of other illnesses, such as upper respiratory tract infection, asthma, and pneumonia. ${ }^{6,7}$ Some of these patients may even present to an outpatient pediatric clinic. ${ }^{6}$ Complications of foreign body aspiration are atelectasis, pneumonia, lung collapse, hypoxic brain injury, and death. Other complications of delayed foreign body removal that have been reported are bronchial granulation tissue, bronchial stenosis, broncho-oesophageal fistula, and opportunistic fungal infection. ${ }^{5,8-10}$

A previous study in Malaysia has shown that the most common foreign body aspirated was peanut, which is comparable to other studies. ${ }^{11,12}$ This is followed by watermelon seed and coconut kernel. Metal objects (toys, springs, hair clips) and plastic objects (ballpoint tips, pencil caps and whistles) were found to be the most common non-food substance aspirated. ${ }^{12}$

The current gold standard of foreign body removal from the airway is via rigid ventilating bronchoscopy under general anesthesia, which serves as diagnostic as well as therapeutic procedure. Flexible bronchoscopy can also be performed and has the advantages of ability to remove foreign bodies located peripherally, such as in the right upper lobe bronchus, and can be used after removal of the foreign body to check for residual foreign bodies in the distal airways. $^{13}$ Additionally, bronchoalveolar lavage can be performed in the same setting. Failure to remove the foreign body or injury to the airway may require surgical intervention, mainly thoracotomy via open or endoscopic approach. $^{14}$

The objective of the present study is to review pediatric patients who underwent bronchoscopy due to suspicion of foreign body aspiration. We aim to identify specific clinical features and investigation results that are associated with the presence of a foreign body. We also reviewed methods of foreign body removal and outcome of each patient.

\section{Method}

This is a retrospective study conducted at a tertiary hospital in Malaysia. The study was done over the period of 10 years, from 2008 to 2018. All children aged $<11$ years old, with suspected foreign body aspiration who underwent bronchoscopy for either diagnostic or therapeutic purposes were included in this study. These children demonstrated either definite history of choking after foreign body ingestion, persistent cough with fever, cyanosis with stridor, or voice change. The following information were retrieved: demographic data, time interval from the onset of symptoms to presentation to hospital, presenting symptoms and signs, examination findings, first-line investigations, the time interval prior to bronchoscopy, intraoperative findings, method of foreign body removal and individual outcome.
Table 1 Age and gender of patients with foreign body aspiration

\begin{tabular}{|l|l|l|l|}
\hline Age group (years) & Male & Female & Total \\
\hline $0-3$ & 6 & 6 & 12 \\
\hline $4-7$ & 1 & 1 & 2 \\
\hline $8-11$ & 1 & 1 & 2 \\
\hline Total & 8 & $\mathbf{8}$ & 16 \\
\hline
\end{tabular}

For these patients, either rigid or flexible bronchoscopy or both were performed by experienced otolaryngologists or pediatric respiratory consultant under general anesthesia. This research has been approved by the Ethical Committee of Malaysia, National Medical Research Register (ID: NMRR19-1004-47455).

\section{Result}

Over the 10-year period, there were 20 cases of suspected pediatric foreign body aspiration. Out of 20 patients, 16 were found to have foreign body aspiration, consisting of 8 boys (50\%) and 8 girls (50\%). These patients' ages ranged between 8 months and 9 years old. The most common age group was $<3$ years old, with 9 patients stratified into this group (75\%) (-Table 1). All these patients did not have significant past medical history, except for one patient with cerebral palsy. Two cases occurred while the children were under the care of babysitters.

Seventeen patients gave definite history of suspected foreign body aspiration or choking episode after eating. Of those patients, 14 had foreign body removed by bronchoscopy (82\%), and no foreign body was found in 3 patients (18\%). Other symptoms experienced by patients with confirmed foreign body aspiration were persistent coughing in 11 patients (69\%), difficulty breathing in 10 patients (69\%), postprandial vomiting in 9 patients (56\%), and change of voice in 4 patients (25\%). There is no significant correlation between symptoms and age.

The most common clinical presentation observed in patients with confirmed foreign body aspiration were stridor in 5 patients (31\%), fever in 5 patients (31\%), followed by cyanosis in 4 patients (25\%). Reduced air entry was the most common lung examination finding, which was present in 12 patients (75\%), and wheezing in 3 patients (19\%). There was no significant correlation between clinical presentation and age.

Chest radiograph was routinely performed for all cases of suspected foreign body aspiration. In patients with confirmed foreign body aspiration, the most common finding was lung hyperinflation in 6 patients (38\%), and pulmonary consolidation and lung collapse in 2 patients (13\%). Only 2 patients (18\%) had a visible foreign body seen on chest radiograph. There was no significant correlation between chest radiograph findings and age. Full blood count was also routinely performed; however, we found that the results were highly variable from normal to high.

For removal of foreign bodies, flexible bronchoscopy with a flexible grasper was used in 8 cases (50\%), and rigid ventilating bronchoscopy was used in 8 cases (50\%). The 
Table 2 Types of foreign body found during bronchoscopy

\begin{tabular}{|c|c|c|c|}
\hline Type of material & Type & Material & Number \\
\hline \multirow[t]{8}{*}{ Organic } & Food & Peanut & 3 \\
\hline & & Sweet & 1 \\
\hline & & Fish ball & 1 \\
\hline & & Chicken meat & 1 \\
\hline & & Cinnamon & 1 \\
\hline & & Chili & 1 \\
\hline & & Fish bone & 1 \\
\hline & & Total & 9 \\
\hline \multirow[t]{8}{*}{ Inorganic } & Stationery & Pen cap & 1 \\
\hline & & Eraser & 1 \\
\hline & & Paper & 1 \\
\hline & Toy & Toy part & 1 \\
\hline & Homeware & Plastic part & 1 \\
\hline & Electronic & LED & 1 \\
\hline & Hardware & Nail & 1 \\
\hline & & Total & 7 \\
\hline
\end{tabular}

Abbreviation: LED, light-emitting diode.

flexible bronchoscopy procedures were performed by the same pediatric respiratory consultant, and the rigid bronchoscopy procedures were performed by different ENT specialists. Among the cases treated with flexible bronchoscopy procedures, difficulties were encountered in 6 of them (75\%), especially in the age group $<3$ years old. These difficulties were foreign body stuck at the tip of the endotracheal (ET) tube lumen during removal, inability to visualize and grasp object as the object was transparent (pen cap), and poor suction ability. Rigid ventilating bronchoscopy with grasping forceps and Hopkins telescope (Karl Storz SE \& Co. KG, Tuttlingen, Germany) was subsequently used with no difficulty. There were no difficulties encountered during foreign body removal using rigid ventilating bronchoscopy. The decision to use either a flexible or rigid ventilating bronchoscope depends on the availability of a pediatric respiratory consultant. In all cases, no complications were encountered during and after procedures. We did not find a foreign body in 4 patients (20\%).

In our study, foreign bodies were found in 16 patients. Nine (56\%) foreign bodies were organic materials, and 7 (44\%) were inorganic materials. The most common organic foreign body found was peanut, whereas the most common inorganic materials found were stationery items (- Table $\mathbf{2}$, -Figs. 1 and 2). There is no significant correlation between age group and the type of foreign body aspirated.

The majority of foreign bodies were lodged in the right bronchus, with 7 cases (43\%), followed by the left bronchus, with 4 cases (25\%), subglottis in 2 cases (13\%), glottis in 2 cases (13\%), and carina in 1 case (6\%) (-Table 3 ). In each age group, the most common site of foreign body lodgment was the right bronchus.

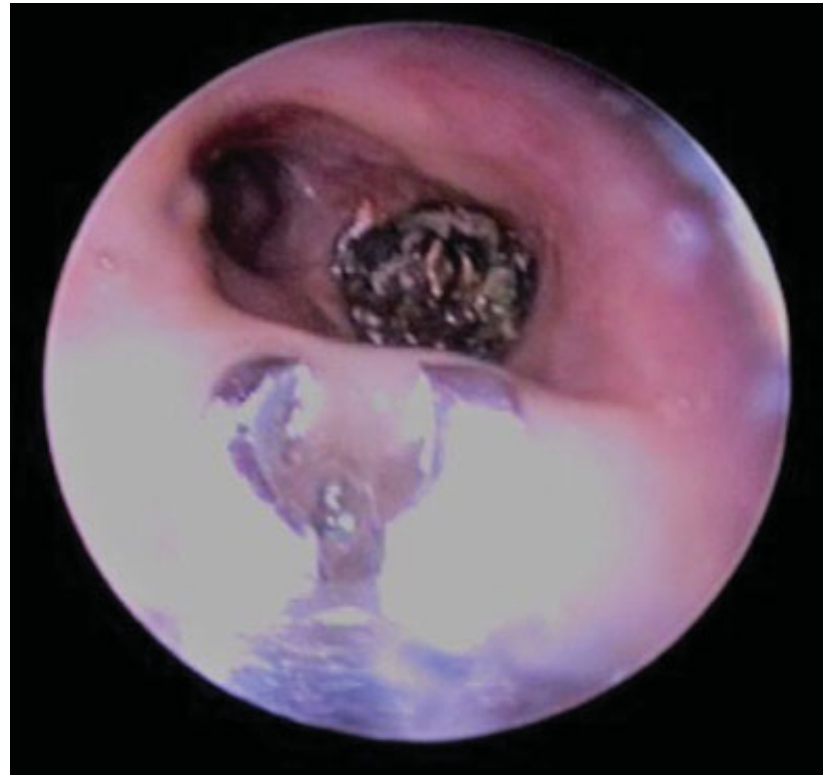

Fig. 1 Cut chili lodged in right bronchus.

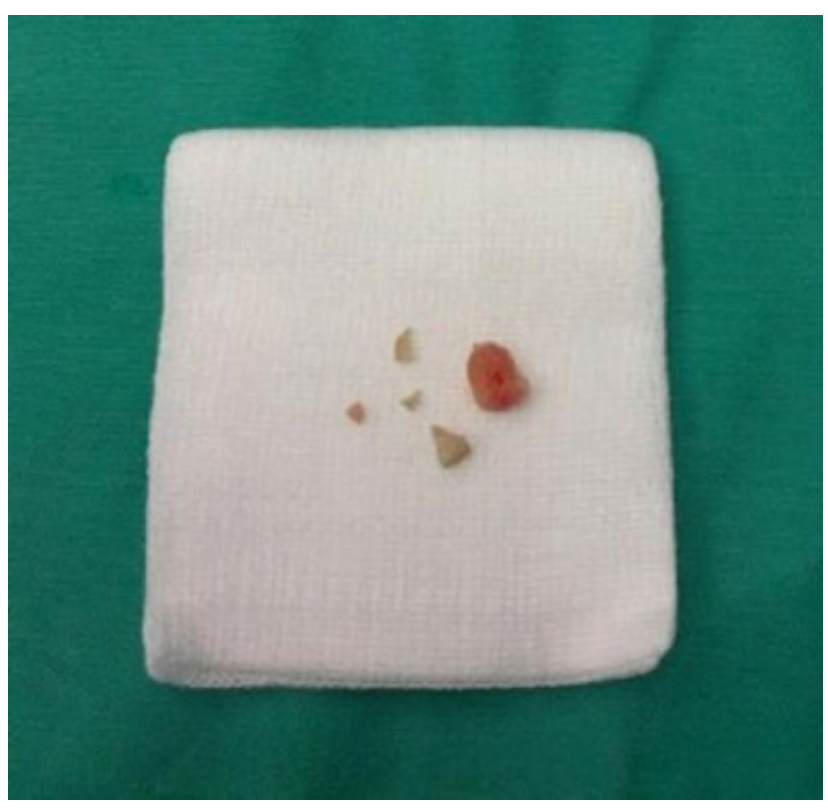

Fig. 2 Pieces of peanuts lodged in right bronchus retrieved.

Table 3 Location of foreign body found during bronchoscopy

\begin{tabular}{|l|l|}
\hline Location & Number \\
\hline Right bronchus & 7 \\
\hline Left bronchus & 4 \\
\hline Glottic & 2 \\
\hline Subglottis & 2 \\
\hline Carina & 1 \\
\hline Total & 16 \\
\hline
\end{tabular}


Table 4 Summary of pediatric foreign body aspiration based on age group

\begin{tabular}{|l|l|l|l|l|l|l|}
\hline $\begin{array}{l}\text { Age group } \\
\text { (years) }\end{array}$ & Gender & $\begin{array}{l}\text { Type of } \\
\text { foreign body }\end{array}$ & $\begin{array}{l}\text { Method of removal } \\
\text { (Rigid/ Flexible) }\end{array}$ & $\begin{array}{l}\text { Difficulty during } \\
\text { removal }\end{array}$ & $\begin{array}{l}\text { Length of } \\
\text { care (days) }\end{array}$ & Complication \\
\hline $0-3$ & Male & Peanut & Rigid & No & 6 & No \\
\hline & & Chicken meat & Flexible & Yes- poor suction & 5 & No \\
\hline & Cinnamon & Flexible & $\begin{array}{l}\text { Yes-reason } \\
\text { not mentioned }\end{array}$ & 3 & No \\
\hline & & Peanut & Flexible & Yes- poor suction & 8 & No \\
\hline & & Paper & Rigid & No & 5 & No \\
\hline & & Peanut & Rigid & No & 2 & No \\
\hline & Female & LED & Rigid & No & 4 & No \\
\hline & & Fish ball & Flexible & Yes-stuck in ET tube & 3 (month) & $\begin{array}{l}\text { Yes-hypoxic } \\
\text { brain injury }\end{array}$ \\
\hline & & Eraser & Rigid & No & 2 & No \\
\hline & & Toy part & Flexible & $\begin{array}{l}\text { Yes- retained below } \\
\text { vocal cord }\end{array}$ & 8 & No \\
\hline & & Flastic part & Rigid & No & 5 & No \\
\hline $4-7$ & Male & Sweet & Rigid & No & 7 & No \\
\hline & Female & Chili & Flexible & No & 10 & No \\
\hline $8-11$ & Male & Nail & Rigid & No & 2 & No \\
\hline & Female & Pen cap & Flexible & $\begin{array}{l}\text { Yes-transparent } \\
\text { object }\end{array}$ & 4 & No \\
\hline
\end{tabular}

Abbreviation: ET, endotracheal; LED, light-emitting diode.

Out of 20, we found that fifteen patients (75\%) presented immediately after the onset of symptoms and five patients (25\%) had delayed presentation after up to seven days of observation at home. Three patients required intubation on arrival to hospital and one of them required cardiopulmonary resuscitation (CPR) for cardiac arrest. All 3 patients were less than 7 years old. Out of these 3 patients, 2 were extubated after foreign body removal and discharged after 5 and 10 days of admission, respectively. One patient developed hypoxic brain injury after CPR.

We also found that 9 patients (56\%) with confirmed foreign body in the airway received delayed treatment. Eight patients (50\%) were in the $<3$ years old age group. These patients were initially treated for tonsillitis, acute bronchiolitis, bronchopneumonia, tuberculosis, respiratory papillomatosis, and foreign body in the esophagus. This caused a delay from 1 day to 2 months in performing the bronchoscopy.

Fifteen patients (94\%) were discharged after 2 to 10 days with no permanent disability as a result of foreign body aspiration. The length of hospital stay was longer in the younger age groups as compared with the 8 to 11 years old age group. One patient $(6 \%)$ in the $<3$-years old age group had prolonged hospital stay for 3 months due to hypoxic brain injury secondary to foreign body aspiration, and the patient required cardiopulmonary resuscitation (CPR) at the emergency department. Prolonged admission was due to recurrent hospital acquired pneumonia, sacral sore, and rehabilitation (-Table 4 ).

\section{Discussion}

Foreign body aspiration in children is known to cause significant morbidity and mortality, as observed in our study. To be able to reach a diagnosis, a high index of suspicion is required. Therefore, it is important to identify demographic information, clinical presentation, and specific features on investigation to ensure immediate treatment is provided to prevent complication.

In our study, female patients (50\%) were equally affected as male patients (50\%) for each age group, with a male to female ratio of $1: 1$. Similar results were also reported in studies conducted in Ghana. ${ }^{3,11}$ However, most studies with larger sample sizes showed male gender preponderance. ${ }^{15-17}$ This is thought to be due to the more adventurous nature of boys. ${ }^{18}$ The peak age for foreign body aspiration was found to be $<3$ years old. This finding corresponded with other studies that have reported foreign body aspiration to be most common in children aged 1 to $3 .^{4,16,19,20}$ Mantel et al reported, in a review of 224 patients, that $81 \%$ of cases were of patients under the age of $3 .^{21}$ Increased risk in young children has been attributed to incomplete dentition due to lack of cuspid molars to grind food adequately and immature swallowing coordination. Consequently, the food remained in the mouth longer, leading to higher risk of aspiration. They also have the tendency to play during food ingestion. Another significant reason is they tend to recognize objects by mouthing, thus causing accidental ingestion. ${ }^{22,23}$ 
We found that presenting symptoms were similar across all age groups. Obtaining a history of suspected foreign body aspiration or choking episode after eating is crucial in achieving diagnosis. Choking has been found to have the highest predictive factor of foreign body aspiration and is present in 75 to $90 \%$ of cases. ${ }^{10,24,25}$ Therefore, it is important to extract the information from parents, patients, or witnesses, as many will only admit after close questioning. ${ }^{26}$ The next most common presenting symptoms are persistent cough (69\%) and difficulty breathing (69\%), as similarly observed in other studies. ${ }^{7,15}$ For this reason, these children are commonly treated for other acute respiratory illnesses, such as asthma and pneumonia. Therefore, in patients with persistent coughing and unresolved pneumonia, foreign body aspiration must be ruled out. Meticulous history taking has been found to be superior to physical examination in diagnosing foreign body aspiration. ${ }^{27}$

We also found that clinical examination was similar across all age groups. The most common examination finding that we observed were reduced breath sound on the affected side (75\%), followed by wheezing (19\%), which are in keeping with studies done in Brazil and Pakistan. ${ }^{28,29}$ These lung examination findings have been cited to have high specificity for foreign body aspiration. ${ }^{28}$ Janahi et al reported that decreased air entry is significantly more common in children with foreign body aspiration. ${ }^{30}$ The classic triad of wheeze, cough, and unilateral decreased breath sounds may not necessarily be present and has been observed in only one third of all cases. ${ }^{10,31}$

Chest radiograph is the first-line investigation done in suspected foreign body aspiration, preferably inspiratory and expiratory radiographs in cooperative children, or decubitus radiographs younger and less cooperative children. ${ }^{8}$ As most objects are radiolucent, the foreign body may not be visible on plain radiograph. Other features to suggest foreign body aspiration are unilateral lung hyperinflation, consolidation, collapse, atelectasis, tracheal shift and mediastinal shift, depending on the site of lodgment. ${ }^{7,32}$ We found that the most common finding in our study is lung hyperinflation on the affected side (38\%) across all age groups, in keeping with other studies. ${ }^{33,34}$ Normal chest radiograph does not exclude the diagnosis, as observed in our study. Previous studies have showed that up to $50 \%$ of cases can have normal chest radiograph findings. ${ }^{27,35}$ Computed tomography (CT) chest can also be performed in selected cases when the diagnosis is in question and to avoid bronchoscopy. ${ }^{36}$ Computed tomography has been found to be $100 \%$ sensitive and $66.7 \%$ specific. It also has a positive predictive value of $93.3 \%$ and negative predictive value of $100 \%$ for detecting foreign body in the airway when compared with findings on rigid bronchoscopy. ${ }^{8}$

Comparable to the literature, our research showed that organic materials were more commonly found than inorganic materials, with peanut being the most commonly aspirated object. ${ }^{11,34,37}$ The most common inorganic materials aspirated were stationery items. However, there was no significant correlation between the types of foreign body and age group. Apart from that, it has been found that the nature of the foreign body may affect clinical presentation. Organic materials, such as nuts, may expand due to absorption of water and break up into smaller pieces. This characteristic is dangerous because patients with partially obstructed airway can develop complete airway obstruction. Furthermore, the pieces of broken up foreign body can be lodged into the distant airway during bronchoscopy, making removal difficult (-Fig. 2). Inorganic materials, in contrast, may cause complete sudden blockage in the tracheobronchial system, causing acute upper airway obstruction. ${ }^{23,38}$

We found that the most common site of foreign body lodgment for all age groups was in the right bronchus, as noted in many other studies. ${ }^{5,7}$ This is due to the anatomy of the right bronchus, which is shorter, wider, more vertical and of larger diameter. ${ }^{4,23,34}$

Effective communication between the surgeon, anesthesiologist, and pediatrician is of utmost importance to ensure optimal care before and after the procedure. The gold standard of removal of foreign body in the airway is via ventilation rigid bronchoscopy under general anesthesia. The optical forceps markedly improved visualization, providing excellent view during the procedure. ${ }^{7}$ The most common difficulties that we encountered during foreign body removal were via flexible bronchoscopy, during which we faced technical issues such as poor suctioning and difficulty in grasping object, especially in age group $<3$ years old. This may be due to the smaller diameter of the flexible bronchoscope and flexible grasper used (Olympus; BF-XP190, 3.1 mm, Tokio, Japan [OD]). Despite the difficulties, we found that it is largely beneficial to assess distal airways for residual foreign body and for bronchial lavage in patients with negative bronchoscopy to obtain culture. Bronchoscopy must be performed as early as possible when there is high index of suspicion to prevent delayed or missed diagnosis. ${ }^{23}$ To reduce these preventable complications associated with delayed or missed diagnosis, many authors advocate for early bronchoscopy rather than observation. Mantor et al proposed that a negative bronchoscopy rate of 10 to $15 \%$ is acceptable. ${ }^{27}$

One of the problems commonly highlighted in the literature in the management of pediatric foreign body aspiration is delay in diagnosis. It leads to increased hospital stay and further respiratory insult. Piva et al reported, in one of the earliest publications on foreign body aspiration, that the most frequent incorrect diagnoses given were asthma, bronchopneumonia, and laryngitis. ${ }^{5}$ In our study, the majority of the patients who received delayed treatment due to delayed diagnosis were $<$ 3 years old. The possible reasons that have been postulated for delay in diagnosis are incomplete history due to unwitnessed choking event, especially in young children; quiescent phase before pneumonia or other complications develop; and foreign bodies not visualized on chest radiograph. ${ }^{8}$

We observed that the length of hospital stay was longer for younger age groups as compared with the 8 to 11 years old age group. This is due to additional observation required for younger children to ensure full recovery with no evidence of complication. Extra caution is also required, especially in aspiration of organic material for late onset complications, such as pneumonia. One patient had, unfortunately, developed hypoxic brain injury secondary to foreign body 
aspiration. The patient had prolonged admission for 3 months due to recurrent hospital acquired pneumonia, sacral sore, and rehabilitation. Unfortunately, the patient passed away 3 years after the event due to severe pneumonia.

A shift toward prevention should be promoted, as foreign body aspiration is a preventable cause of childhood morbidity and mortality. In general, greater efforts should be made to increase awareness amongst parents, babysitters, and nursery schools of foreign body aspiration and its lethal complications. This can be done by national educational campaigns and media programs broadcast. New parents should be informed about the types of foreign bodies that are commonly aspirated and prevention methods prior to discharge after delivery. Safety guidelines in nursery and elementary schools must be updated regularly. For older children, the Heimlich maneuver technique should be incorporated into first-aid education in school. Lastly, stricter rules should be introduced for toy manufacturers in providing obvious warning labels for high-risk items.

We acknowledge that a limitation of our study is the limited sample size, especially in older age group.

\section{Conclusion}

There is no significant correlation between age and type of foreign body aspiration in children. Clinical presentation and chest radiograph findings are comparable across all age groups. The most common site of foreign body lodgment for all age groups was in the right bronchus. Removal via flexible bronchoscopy was the method that encountered the most difficulties, especially in children $<3$ years old. The majority of the patients who received delayed treatment due to delayed diagnosis were $<3$ years old, and the length of hospital stay was longer for younger age groups as compared with the 8 to 11 years old age group. We emphasize the importance of prevention by means of parental and public education, strict guidelines to toy manufacturers, and national level campaigns.

\section{Conflict of Interest}

The authors have no conflict of interests to declare.

\section{References}

1 Okonkwo OC, Simons A, Nichani J; North West ENT Research Collaborative. Paediatric airway foreign body - The human factors influencing patient safety in our hospitals. Int J Pediatr Otorhinolaryngol 2016;91:100-104

2 Brkic F, Umihanic S, Altumbabic $\mathrm{H}$, et al. Death as a Consequence of Foreign Body Aspiration in Children. Med Arh 2018;72(03):220-223

3 Adjeso T, Damah MC, Murphy JP, Anyomih TTK. Foreign Body Aspiration in Northern Ghana: A Review of Pediatric Patients. Int J Otolaryngol 2017;2017:1478795

4 Naragund AI, Mudhol RS, Harugop AS, Patil PH, Hajare PS, Metgudmath VV. Tracheo-bronchial foreign body aspiration in children: a one year descriptive study. Indian J Otolaryngol Head Neck Surg 2014;66(Suppl 1):180-185

5 Cassol V, Pereire AM, Zorzela LM, Becker MM, Barreto SSM. Foreign body in children's airway. J Pneumol 2003;29(03):139-144
6 Baram A, Kakamad FH, Bakir DA. Scarf pin-related hijab syndrome: A new name for an unusual type of foreign body aspiration. J Int Med Res 2017;45(06):2078-2084

7 Kaur K, Sonkhya N, Bapna AS. Foreign bodies in the tracheobronchial tree: A prospective study of fifty cases. Indian J Otolaryngol Head Neck Surg 2002;54(01):30-34

8 Srivastava G. Airway Foreign Bodies in Children. Clin Pediatr Emerg Med 2010;11(02):67-72

9 Dehghani N, Ludemann J. Aspirated foreign bodies in children: BC Children's Hospital emergency room protocol. BCMJ 2008;50(05): 252-256

10 Mitchell CA, Kreiger P, Goff C, Shah UK. Pediatric foreign body aspiration: A nidus for Aspergillus colonization. Int J Pediatr Otorhinolaryngol 2015;79(06):938-940

11 Kitcher ED. Foreign body inhalation: a review of patients at the Korle Bu Teaching Hospital, Accra, Ghana. West Afr J Med 2009;28 (06):368-370

12 Gendeh BS, Gendeh HS, Purnima S, Comoretto RI, Gregori D, Gulati A. Inhaled Foreign Body Impaction: A Review of Literature in Malaysian Children. Indian J Pediatr 2019;86(Suppl 1):20-24

13 Aslan A, Topal E, Eyuboglu T, Unal Y. Which bronchoscopy procedure should be chosen for foreign body aspiration in children: Rigid, flexible or combined? Eur Respir J 2013;42:1244

14 Asaf BB, Vijay CL, Bishnoi S, Dua N, Kumar A. Thoracoscopic foreign body removal and repair of bronchus intermedius following injury during failed bronchoscopic retrieval. Lung India 2017; 34(02):182-184

15 Yadav SPS, Singh J, Aggarwal N, Goel A. Airway foreign bodies in children: experience of 132 cases. Singapore Med J 2007;48(09): 850-853

16 Rothmann BF, Boeckman CR. Foreign bodies in the larynx and tracheobronchial tree in children. A review of 225 cases. Ann Otol Rhinol Laryngol 1980;89(5 Pt 1):434-436

17 Swanson KL, Prakash UB, Midthun DE, et al. Flexible bronchoscopic management of airway foreign bodies in children. Chest 2002;121(05):1695-1700

18 Tan HK, Brown K, McGill T, Kenna MA, Lund DP, Healy GB. Airway foreign bodies (FB): a 10-year review. Int J Pediatr Otorhinolaryngol 2000;56(02):91-99

19 Senkaya I, Sağdiç K, Gebitekin C, Yilmaz M, Ozkan H, Cengiz M. Management of foreign body aspiration in infancy and childhood. A life-threatening problem. Turk J Pediatr 1997;39(03): 353-362

20 McGuirt WF, Holmes KD, Feehs R, Browne JD. Tracheobronchial foreign bodies. Laryngoscope 1988;98(6 Pt 1):615-618

21 Mantel K, Butenandt I. Tracheobronchial foreign body aspiration in childhood. A report on 224 cases. Eur J Pediatr 1986;145(03): 211-216

22 Zur KB, Litman RS. Pediatric airway foreign body retrieval: surgical and anesthetic perspectives. Paediatr Anaesth 2009;19 (Suppl 1):109-117

23 Yetim TD, Bayarogulları H, Arıca V, Akcora B, Arıca SG, Tutanc M. Foreign Body Aspiration in Children; Analysis of 42 Cases. J Pulm Respir Med 2012;1(03):61-67

24 Even L, Heno N, Talmon Y, Samet E, Zonis Z, Kugelman A. Diagnostic evaluation of foreign body aspiration in children: a prospective study. J Pediatr Surg 2005;40(07):1122-1127

25 Eren S, Balci AE, Dikici B, Doblan M, Eren MN. Foreign body aspiration in children: experience of 1160 cases. Ann Trop Paediatr 2003;23(01):31-37

26 Merchant SN, Kirtane MV, Shah KL, Karnik PP. Foreign bodies in the bronchi (a 10 year review of 132 cases). J Postgrad Med 1984; 30(04):219-223

27 Rovin JD, Rodgers BM. Pediatric foreign body aspiration. Pediatr Rev 2000;21(03):86-90

28 Fraga AdeM, Reis MC, Zambon MP, Toro IC, Ribeiro JD, Baracat EC. Foreign body aspiration in children: clinical aspects, radiological 
aspects and bronchoscopic treatment. J Bras Pneumol 2008;34 (02):74-82

29 Tariq P. Foreign body aspiration in children-a persistent problem. J Pak Med Assoc 1999;49(02):33-36

30 Janahi IA, Khan S, Chandra P, et al. A new clinical algorithm scoring for management of suspected foreign body aspiration in children. BMC Pulm Med 2017;17(01):61

31 Midulla F, Guidi R, Barbato A, et al. Foreign body aspiration in children. Pediatr Int 2005;47(06):663-668

32 Svedström E, Puhakka H, Kero P. How accurate is chest radiography in the diagnosis of tracheobronchial foreign bodies in children? Pediatr Radiol 1989;19(08):520-522

33 Cataneo AJ, Reibscheid SM, Ruiz Júnior RL, Ferrari GF. Foreign body in the tracheobronchial tree. Clin Pediatr (Phila) 1997;36(12): 701-706
34 Parameswaran N, Das S, Biswal N. Respiratory Morbidity Following Foreign Body Aspiration Among South Indian Children: A Descriptive Study. Cureus 2018;10(11):e3629. Doi: 10.7759/cureus.3629

35 Sultan TA, van As AB. Review of tracheobronchial foreign body aspiration in the South African paediatric age group. J Thorac Dis 2016;8(12):3787-3796

36 Passàli D, Lauriello M, Bellussi L, Passali GC, Passali FM, Gregori D. Foreign body inhalation in children: an update. Acta Otorhinolaryngol Ital 2010;30(01):27-32

37 Chiu CY, Wong KS, Lai SH, Hsia SH, Wu CT. Factors predicting early diagnosis of foreign body aspiration in children. Pediatr Emerg Care 2005;21(03):161-164

38 Kendigelen P. The anaesthetic consideration of tracheobronchial foreign body aspiration in children. J Thorac Dis 2016;8(12): 3803-3807 